\title{
JUVENTUDE, DROGAS E RACISMO: REDUÇÃO DE DANOS E COMBATE AO GENOCÍDIO DA JUVENTUDE NEGRA
}

\author{
Francisco José Pires ${ }^{1}$
}

\section{RESUMO}

Este relato de experiência procura diagnosticar, analisar e vivenciar os problemas enfrentados pela Juventude negra em relação às drogas, ao racismo, à redução de danos e ao combate ao genocídio da juventude negra, como recursos didáticos pedagógicos. As Tecnologias da Informação e da Comunicação (TICs) apontam para a importância da internet, web, inteligência coletiva e blog como recursos e estratégias pedagógicas. Para efetivar a pesquisa, realizamos uma oficina com os alunos da disciplina Sociologia Jurídica, em uma comunidade da Zona Leste de São Paulo, tornando-os protagonistas, interagindo com os jovens da comunidade, no intuito de esclarecer sobre o perigo das drogas, como também para combater o racismo. A presente pesquisa culminou com um Júri Simulado em uma universidade em São Paulo. O trabalho empírico foi realizado para valorizar o ponto de vista do cidadão na avaliação dos serviços oferecidos pelos equipamentos públicos. Após as reflexões e a materialização da atividade, ficou evidente que a questão racial ainda não é encarada naturalmente pelos estudantes.

Palavras-chave: Educação. Inclusão Social. Juventude Negra. Racismo.

\section{INTRODUÇÃO}

O presente relato de experiências tem como tema Juventude, Drogas e Racismo: redução de danos e combate ao genocídio da juventude negra. Procura-se analisar a questão das condições em que vive essa população no Brasil e as políticas públicas implantadas neste contexto, que podem definir o tipo de cidadão que ocupa os espaços das grandes cidades.

As inquietações que nos impulsionaram à escolha do tema que subjaz à pesquisa provêm da constatação de que a questão das políticas públicas para redução de danos e combate ao genocídio dessa parcela da população ainda é incipiente. E as condições precárias da juventude negra se converteram, na década de 1990 e na primeira década do século XXI, em problemas emergentes carentes de soluções por parte do poder público.

Diante disso, este relato pretende levantar as políticas públicas implantadas pelo Governo brasileiro com vistas à melhoria da qualidade de vida da juventude negra, a partir de 1990, com investigação centrada nas cidades do Rio de Janeiro e de São Paulo.

As pesquisas apontam que com um processo de globalização desigual, a incerteza global torna-se ainda mais angustiante pela ausência de processos educativos e projetos sociais

1 Doutor e Mestre em Integração da América Latina, Jornalista, Geógrafo e Pedagogo. E-mail: fco.pires@hotmail.com 
consistentes que possam reduzir danos e qualificar o jovem negro para o exercício da cidadania e para o mercado de trabalho, atendendo a demanda educacional e profissional que se faz necessária para as exigências do mundo atual.

Nesse sentido este relato procura diagnosticar, analisar e vivenciar os problemas enfrentados pela Juventude negra em relação às drogas e ao racismo, utilizando como recurso didático- pedagógico as Tecnologias da Informação e da Comunicação (TICs), apontando a importância da internet, web, inteligência coletiva e blog, enquanto recursos e estratégias pedagógicas.

O presente trabalho objetiva: 1) estudar a qualidade de vida da juventude negra na Zona Leste da cidade de São Paulo; 2) analisar as condições e os contextos sociopolítico, econômico e cultural em que se materializam o cotidiano dos jovens negros, a partir das políticas públicas empreendidas; e 3) identificar pontos de interesses comuns para a realização de estudos conjuntos entre pesquisadores ou centros de pesquisas.

Para materializar esses objetivos, partimos de uma caracterização global dos processos de exclusão da juventude negra, ocorridos a partir dos anos 90, contextualizando as particularidades do objeto de estudo, o que contribuiu para se desenhar o perfil dos jovens negros. Além disso, foram selecionadas informações que permitem apreciar a magnitude das condições em que vive a juventude negra, o uso de drogas e o genocídio, precisando variáveis comparativas da intervenção do Estado no processo de redução de danos da juventude negra, identificando as principais limitações que levam o tratamento estatístico oficial a uma compreensão do foco deste trabalho.

Por fim, foi realizado um levantamento da produção de destaque dos últimos anos, especialmente, sem detrimento de trabalhos significativos realizados anteriormente, identificando as tendências centrais das abordagens conceituais vigentes e predominantes, pressupostos teóricos, temáticas privilegiadas, preocupações centrais e principais lacunas do conhecimento sobre o papel do Estado na redução de danos da juventude negra.

As considerações colocadas ao longo do trabalho têm seu conteúdo referenciado ao contexto brasileiro, especialmente no Rio de Janeiro e em São Paulo, no que se refere à relação entre as políticas públicas e exclusão/inclusão da juventude negra. Contudo, trata-se de um esforço de compreensão de uma temática posta para discussão, sem pretensão de esgotar o assunto, dada a abrangência e complexidade de que se reveste.

Em consequência, avançar na pesquisa sobre a relação entre políticas públicas e exclusão/inclusão da juventude negra no Rio de Janeiro e em São Paulo significa aprofundar a 
compreensão das transformações dos espaços dessas cidades, o que equivale a um melhor entendimento da organização da sociedade e de suas estruturas no passado e no presente.

Esta pesquisa é justificada pelo fato de que as produções científicas sobre a relação existente entre políticas públicas e exclusão/inclusão da juventude negra no Rio de Janeiro e em São Paulo ainda são incipientes. Interessa neste trabalho resgatar instrumentos que possam contribuir para a ciência no contexto de um mundo globalizado, uma vez que se faz necessário o registro de novas formas de atuação do Estado, considerando as transformações das relações sociais que se dão dentro de um processo global amplo, apontando processos sociais relevantes na atualidade.

Nesse sentido, pretende-se discutir questões, como: que medidas poderiam desencadear um processo de recuperação da Educação para redução de danos da juventude negra? Qual o papel das universidades no atual cenário mundial? Qual a contribuição das Tecnologias da Informação e da Comunicação na construção do conhecimento? Como perceber no processo de modernização aspectos das relações sociais capitalistas e seu impacto no conjunto da sociedade?

Com isso, pretende-se contribuir para a compreensão de como se deu a intervenção do Estado a partir dos anos 90 no Brasil, reelaborando aspectos da própria vida social. A relação políticas públicas e exclusão/inclusão da juventude negra é o paradigma com o qual se espera responder tais indagações.

Neste estudo, o relato de experiências e materializa a partir do plano de aula e do uso das ferramentas de interatividade como recursos e estratégias pedagógicas, no intuito de refletir acerca da relevância das tecnologias no processo de ensino-aprendizagem. Para tanto, foi realizada uma oficina intitulada Juventude, drogas e racismo: redução de danos e combate ao genocídio da juventude negra, com recursos didático-pedagógicos convencionais e com as Tecnologias da Informação e da Comunicação.

Busca-se, portanto, uma abordagem que considera a crise de paradigma como uma questão social, com destaque para inclusão/exclusão da Juventude negra, drogas e racismo e o papel do Estado na consecução de uma política pública que seja capaz de resolver o problema da violência urbana com a redução de danos.

\section{FUNDAMENTAÇÃO TEÓRICA}

Vale ressaltar que o período objeto desta reflexão é especialmente a década de 90 do século XX e o início do século XXI, por serem momentos em que se registram inúmeros casos 
de agressão e racismo contra a juventude negra. Ademais, apesar das políticas públicas implantadas nos últimos 12 anos, verifica-se que a exclusão social, provocada especialmente pelo racismo e pelo uso de entorpecentes, é alarmante.

Isso significa que as gestões anteriores aos anos 90 começaram em um momento ainda nebuloso, no bojo do processo de redemocratização do país, e concluíram seus governos em um contexto de redesenhar um mapa social das condições de vida da juventude negra, especialmente no Rio de Janeiro e em São Paulo. Nesses termos, os objetivos e o perfil da pesquisa foram atravessados por uma onda de transformações culturais, políticas e econômicas que será necessariamente considerada.

Rodrigues (1957, p. 35) já denunciava que,

[...] é preciso romper com os silêncios e as ausências produzidos pelo racismo brasileiro, que elege jovens negros como alvo privilegiado de suspeição e como representantes da violência, negando a esses sujeitos direitos sociais básicos e o reconhecimento da positividade e da legitimidade de suas trajetórias.

O escritor, insatisfeito com a questão da discriminação racial contra os jovens no Brasil, acrescenta:

[...] Não caçamos pretos, no meio da rua, a pauladas, como nos Estados Unidos. Mas fazemos o que talvez seja pior. A vida do preto brasileiro é toda tecida de humilhações. Nós tratamos com uma cordialidade que é o disfarce pusilânime de um desprezo que fermenta em nós, dia e noite (RODRIGUES,1957, p. 36).

Comungando com essas ideias, é possível afirmar que as políticas públicas urbanas empreendidas no Brasil em tempos de globalização aprofundam a desigualdade social, especialmente da juventude negra se comparada aos demais componentes da sociedade brasileira, pois ao mesmo tempo em que aparentemente proporciona a construção e execução de um projeto de inclusão, impulsiona verdadeiro estado de exclusão social para a maioria absoluta da população, especialmente os jovens negros.

Nesse sentido, o procedimento de identificar características das políticas públicas em relação às drogas, racismo, redução de danos e combate ao genocídio da juventude negra, recursos investidos e resultados obtidos, permite formular parâmetros de avaliação e também o estabelecimento de referenciais para padrões mínimos de investimentos.

Nessa perspectiva, busca-se identificar nas políticas públicas implantadas sobre a problemática posta para discussão, alguns indicadores que permitam medir resultados na 
melhoria da média e também na melhoria do patamar inferior da sociedade, ou seja, capacidade de promover a inclusão social.

Ao analisar a literatura sobre o racismo, observa-se que, de um modo geral, existe um ponto de convergência entre os pesquisadores, pois a maioria se preocupa em estudar os danos provocados pelo uso de drogas e o racismo contra a juventude negra. Sobre essa temática, Ribeiro (1995) afirma que:

[...] somos um povo estruturalmente marcado, portanto, por uma histórica cultura autoritária, classista e racista [...]a mais terrível de nossas heranças é esta de levar sempre conosco a cicatriz de torturador impressa na alma e pronta a explodir na brutalidade racista e classista (RIBEIRO, 1995, p.120).

Essa cultura racista e discriminatória que separa os direitos entre ricos e pobres, entre pretos e brancos aprofundando a desigualdade social é potencializada em violência, muitas vezes de maneira camuflada gerando uma grande diferença entre aparência e essência. Sobre essa questão, Odália (1993, p.22-23) enfatiza que "nem sempre a violência se apresenta como um ato, como uma relação, como um fato, que possua estrutura facilmente identificável”. E prossegue,

$\mathrm{O}$ ato violento se insinua, frequentemente, como um ato natural, cuja essência passa despercebida. Perceber um ato como violento demanda do homem um esforço para superar sua aparência de ato rotineiro, natural e como que inscrito na ordem das coisas (ODÁLIA, 1993, p.22-23).

Diante do exposto, observa-se que os danos causados pela violência, especialmente contra a juventude negra, é frequentemente camuflada, sendo revelada nas comunidades carentes na vivência cotidiana.

Ainda, vale mencionar as dificuldades enfrentadas para levantar material teórico para sobre o tema deste estudo. Tal quadro se registra, devido à escassez de publicações. $\mathrm{O}$ que se encontra com mais facilidade são os registros oficiais publicados pelas Secretarias de Estado e organismos estatais.

\section{METODOLOGIA}

A presente pesquisa define-se como um estudo de cunho qualitativo, interdisciplinar e teórico-bibliográfico como itinerário para compreender alguns problemas enfrentados pelos jovens negros. Acerca das pesquisas qualitativas, Patton (1986) explicita: 
A principal característica das pesquisas qualitativas é o fato de que estas seguem a tradição compreensiva ou interpretativa. Isto significa que essas pesquisas partem do pressuposto de que as pessoas agem em função de suas crenças, percepções, sentimentos e valores e que seu comportamento tem sempre um sentido, um significado que não se dá a conhecer de modo imediato (PATTON, 1986 apud MAZZOTTI; GEWANDSZNAJDER, 1988, p.131).

A reflexão constrói-se a partir de um trabalho de recopilação, revisão bibliográfica e análise de dados, que tomam dimensão à medida que se compara as políticas públicas implantadas na perspectiva da inclusão social da juventude negra.

Para se estabelecer estreita relação entre a teoria e a prática, assim como constatar os fatos, realizou-se uma pesquisa empírica com os alunos do curso de Direito de uma Universidade em São Paulo, na disciplina de Sociologia Jurídica, em uma comunidade da Zona Leste, na perspectiva de esclarecer a juventude que ali reside sobre o perigo das drogas e o combate ao racismo, com vistas à redução de danos e combate ao genocídio dessa população.

\section{RELATO DA EXPERIÊNCIA APLICADA}

Foram desenvolvidas duas aulas, conforme plano a seguir:

- Objetivo: Realização de uma oficina em uma comunidade, utilizando-se de diferentes ferramentas de interatividade;

- Conteúdos: Introdução e conceitos de Juventude, drogas e racismo: redução de danos e combate ao genocídio da juventude negra;

- Metodologia de Ensino: Exposição oral do tema, explicando os objetivos da atividade, métodos e avaliação. Em seguida, aula teórico-prática no laboratório de informática; aula prática na praça com uma palestra a partir de uma roda de conversa, seguida de uma oficina sobre o tema e de uma pesquisa com a juventude daquela comunidade. $\mathrm{O}$ fechamento das ações didáticas foi marcado com um Júri Simulado.

- Recursos de Apoio: Data Show, utilização da internet, vídeo, web e pesquisa em blog sobre o tema, texto de apoio.

Após uma visita técnica na comunidade, formou-se um Júri iniciado com uma discussão da situação apresentada, a saber: o caso da Joana Elisa da Silva Cesário, que se sente discriminada pelo patrão. Posta a questão para discussão, não houve consenso.

Para o Júri, os participantes da pesquisa foram divididos em 2 grupos, denominados A e B. O Grupo A defendia a ideia de ter havido discriminação, levantando a questão acerca dos patrões terem sugerido que a estagiária esticasse o cabelo. Os participantes argumentaram que 
desde a escravidão o negro sofre com a violência do preconceito; que o preconceito é uma questão ideológica, pois está arraigado na mente das pessoas desde a formação do povo brasileiro; e que os cidadãos não poupam a oportunidade de tratar o negro como inferior.

Já o Grupo B defendeu que não houve situação de preconceito, argumentando que o Colégio só estava protegendo a estagiária e que a imagem é muito importante, principalmente numa instituição na qual a relação com o público externo é direta. Segundo o grupo, a Instituição de Ensino objetivou colocá-la em uma situação de igualdade social.

Após o debate, os participantes assistiram ao vídeo "Manifesto Porta na Cara - Flagrante na agência bancária", estabelecendo uma relação entre a situação apresentada no vídeo e o contexto da realidade em que vivem os jovens negros na Zona Leste de São Paulo. Grande parte dos alunos da Universidade e os adolescentes da comunidade ficaram indignados com o pouco caso que se faz, em geral, com a situação do negro no Brasil.

Cabe registrar que a turma levou a atividade muito a sério e, em nenhum momento, houve intenção explícita de julgar, no sentido de condenar ou livrar alguém de uma situação. Foi uma atividade muito prazerosa, já que os estudantes ficaram empolgados em discutir o tema em outras aulas de Sociologia Jurídica, inclusive deram a ideia de pesquisar sobre os direitos específicos do negro no Brasil hoje e fazer um painel no Hall de entrada da Universidade, além de disponibilizar o conteúdo no blog criado para este curso. Por fim, foram selecionadas as informações e extraídas algumas conclusões para redigir o relatório final com os resultados da experiência.

\section{CONSIDERAÇÕES FINAIS}

Conforme assinalado no início deste trabalho, a preocupação a priori foi analisar e entender a problemática que intitulamos Juventude negra, drogas e racismo: redução de danos e combate ao genocídio da juventude negra. Ao longo da trajetória, surgiram diferentes ideias, pensamentos e reflexões que paulatinamente tomaram dimensão no corpo do trabalho, elencadas a seguir.

As energias despendidas no esforço de compreensão do processo de exclusão/inclusão nas cidades do Rio de Janeiro e São Paulo, e a configuração do atual desenho do perfil dos jovens negros, fluíram, à medida que se tomou contato direto com a literatura que discute a questão. Inicialmente, interessava entender o problema da violência entre representações e 
realidade, uma vez que esse tema é recorrente na vida cotidiana das pessoas, especialmente da juventude negra.

Nesse sentido, entender as políticas públicas de geração de redução de danos nesse contexto foi o viés que se delineou no sentido de contribuir para o debate desta problemática, assim como para pensar alternativas possíveis para o enfrentamento da violência e da discriminação racial, face às ocorrências que se fazem presentes no cotidiano das pessoas.

Quando se examina os conceitos, as teorias sobre a temática posta para discussão, e as pesquisas realizadas, observa-se que em São Paulo e no Rio de Janeiro existe uma singularidade no processo de exclusão social, visto que, de um modo geral, a reprodução do capital se dá em bases desiguais, gerando uma periferia muito pobre nas grandes cidades. Periferia que nem sempre usufrui dos bens e serviços produzidos pela sua própria força de trabalho. Todavia, essa periferia que se forma, contribui para a formação das áreas metropolitanas, assim como à medida que as camadas pobres e médias se afastam do centro, liberam a reorganização do espaço com a criação de novos bens e serviços que vão surgindo no cotidiano das cidades.

Uma vez colocadas inúmeras questões suscitadas pelas políticas públicas em vigor no Brasil a partir de 1980 e especialmente na década de 1990, tomando como referencial as Regiões Metropolitanas do Rio de Janeiro e de São Paulo, algumas questões são consideradas importantes e merecem destaque: os resultados do estudo não pretendem ser taxativos, assumindo o risco de "não estar tudo o que é ou, ainda, de não ser tudo o que está"; e as reflexões acerca do conhecimento do espaço estudado, por ter uma finalidade social, apenas intencionam que futuros pesquisadores possam avaliá-las, acrescentá-las, aprofundá-las ou refutá-las, de acordo com a flexibilidade, a provisoriedade e a relatividade do próprio conhecimento.

Após as reflexões e a materialização da atividade proposta, ficou evidente que a questão racial não é encarada naturalmente pelos estudantes. A sociedade brasileira ainda continua com certa nebulosidade em relação à percepção do racismo. Esta é uma questão velada por grande parte da população, visto que muitas pessoas têm preconceito, mas não assumem.

A maior parte dos jovens entende que a diversidade racial é normal e que a cada dia que passa a sociedade avança, porém em passos lentos. Percebem que a desigualdade existe, mas não admitem que seja somente por ser negro. Segundo suas concepções, a desigualdade é aparente em todas as etnias.

No tocante à questão da democracia racial, foi tratada com muita cautela no debate, pois ficou evidente que os discentes a aceitam quando é com os outros, é como se eles olhassem por 
uma ótica, de longe, mas quando se aproxima da situação, argumentam: "Peraí, agora é diferente".

Acreditam que no cotidiano existe o preconceito, mas dão uma contrapartida argumentando que o negro também tem preconceito contra brancos, querem todos os direitos, se reservam em grupos segregados e quando estão no poder agem de maneira discriminatória contra os brancos, como se fosse uma revanche. A branquitude se coloca como superiora de maneira camuflada, não admitida.

Durante o Júri, os alunos agiram muito bem, foi uma atividade em perfeita interação, até por ser uma turma do curso de Direito, eles já têm essa prática de Júri Simulado. No caso do debate, a turma reagiu dentro dos padrões de normalidade, sem piada nem risadas desagradáveis.

Cabe ressaltar que o Estado insiste na tese do país paraíso das raças, porem não é o que apontam as pesquisas. Em resposta a uma consulta feita pelo Comitê para a eliminação da Discriminação Racial - CEDR, os dados oficiais apresentam a imagem do descaso com os jovens negros no Brasil, quando o Estado assim se manifesta:

Tenho a honra de informar-lhe que, uma vez que a discriminação racial não existe no Brasil o Governo brasileiro não vê necessidade de adotar medidas esporádicas de natureza legislativa, judicial e administrativa a fim de assegurar a igualdade das raças (SILVA, 2008, p.94).

Em contraponto a essa resposta, o Brasil é apresentado nas estatísticas como um dos países com maior quantidade de casos de homicídios no mundo. Os registros apontam que "56 mil pessoas foram mortas em 2012". Nesse sentido, no que se refere aos dados reais, há verdadeiros estereótipos negativos associados à juventude, notadamente aos jovens negros que vivem em comunidades alijadas do processo de inclusão, especialmente nos Estados do Rio de Janeiro e de São Paulo, contribuindo para a banalização e a naturalização da violência.

Na perspectiva de destacar esses fatos, é possível afirmar que:

Em 2012, mais de 50\% de todas as vítimas de homicídios tinham entre 15 e 29 anos e, destes, 77\% eram negros. [...] Em um período de dez anos (20052014), foram registrados 8.466 casos de homicídio decorrente de intervenção policial no estado do Rio de Janeiro; 5.132 casos apenas na capital. Apesar da tendência de queda observada a partir de 2011, um aumento de quase 39,4\% foi verificado entre 2013 e 2014. O número de pessoas mortas pela Polícia representa parcela significativa do total de homicídios. Em 2014, por exemplo, os homicídios praticados por policiais em serviço corresponderam a $15,6 \%$ do número total de homicídios na cidade do Rio de Janeiro. (ANISTIA INTERNACIONAL, 2015). 
Se compararmos os dados do Rio de Janeiro com São Paulo em relação às taxas de homicídios, levando em conta um total de 100 mil habitantes, há de se considerar que a diferença é pouco significativa, pois de acordo com dados do SIM/SVS/MS, em 1998 o Estado do Rio de Janeiro era responsável por 55,3, ocupando o $3^{\circ}$ lugar no ordenamento nacional e em 2012 28,3, ocupando o $18^{\circ}$ lugar, enquanto São Paulo foi responsável por 39,7 e o $5^{\circ}$ na classificação e 15,1 e $26^{\circ}$ respectivamente no período observado.

Finalizando as ideias expostas em função dessa análise, incorpora-se o pensamento de Santos (2003):

\footnotetext{
A velocidade e o tempo real não podem ser distribuídos e usados igualmente por todos. A promessa de que as técnicas contemporâneas pudessem melhorar a existência de todos cai por terra. Observa-se a expansão da escassez, atingindo as classes médias e criando mais pobres (SANTOS, 2003, p.86).
}

Assim, há de se considerar que a questão da exclusão deverá ser discutida no âmbito das políticas públicas, especialmente da educação, pois os saberes escolares e seu relacionamento com outros saberes socialmente produzidos podem contribuir para a inserção do sujeito no mercado de trabalho e, consequentemente, para o exercício da cidadania.

Acredita-se que a globalização viabilizou uma enorme difusão de informações. O grande resultado é a comunicação que realmente está sem limites físicos de manipulação. Nesse sentido, a escola se tornou anacrônica à medida que não conseguiu acompanhar a concorrência dos meios de comunicação, principalmente as Tecnologias da Informação e da Comunicação no processo ensino e aprendizagem.

Talvez seja um sonho, uma utopia, mas é preciso acreditar e impulsionar essa humanidade para a felicidade individual e coletiva em um contexto social justo, na luta pela equidade social desejada. Por fim, fica a seguinte reflexão: será que a pós-modernidade vai resolver o problema da educação, da discriminação, do racismo e da violência contra a juventude negra?

\section{REFERÊNCIAS}

ABRAMOVAY, Miriam; CASTRO, Mary. Drogas nas escolas. Brasília: UNESCO; Rede Pitágoras, 2002.

ANISTIA INTERNACIONAL. Você matou meu filho: homicídios cometidos pela polícia militar na cidade do Rio de Janeiro. Rio de Janeiro: Anistia Internacional, 2015. Disponível em: 
https://anistia.org.br/wp-content/uploads/2015/07/Voce-matou-meu-filho_AnistiaInternacional-2015.pdf. Acesso em: 29 de janeiro de 2020.

ASSOCIAÇÃO BRASILEIRA DE NORMAS TÉCNICAS. NBR - 6023.Informação e documentação: elaboração: referências. Rio de Janeiro, 2002.

BRASIL. Diretrizes para projetos de redução de danos. Brasília: Ministério da Saúde; Secretaria de Projetos Especiais de Saúde; Coordenação Nacional de Doenças Sexualmente Transmissíveis.

FREIRE, Paulo. Pedagogia do Oprimido. 7. ed. Rio de Janeiro: Paz e Terra,1987, p. 39.

GUIMARÃES, Antonio Sérgio Alfredo. Racismo e antiracismo no Brasil. São Paulo: Editora 34, 2005.

MAZZOTTI, Alda Judith Alves ; GEWANDSZNAJDER, Fernando. O Método nas Ciências Naturais e Sociais: Pesquisa Quantitativa e Qualitativa. São Paulo: Pioneira, 1988.

ODÁlIA, N. O Que é Violência. Coleção Primeiros Passos. São Paulo: Brasiliense, 1993.

RIBEIRO, Darcy. O Povo brasileiro: a formação e o sentido do Brasil. São Paulo: Companhia das Letras, 1995.

RIBEIRO, Janaína de Oliveira Nunes. Uso Pedagógico das Ferramentas de Interatividade. Juiz de Fora: Universidade Federal de Juiz de Fora, 2015.

RODRIGUES, Nelson. Abdias: o negro autêntico. In: Nascimento, Abdias. Última Hora. Rio de Janeiro: [S.1.: s.n.], 1957. p. 157- 158.

SANTOS, Milton. Por uma outra globalização: do pensamento único à consciência universal. 10. ed. Rio de Janeiro: Record, 2003.

SILVA, Silvio José Albuquerque E. Combate ao racismo. Brasília: Fundação Alexandre de Gusmão, 2008. 